\title{
Cerebellar and Fourth Ventricle Ependymal Tumor
}

National Cancer Institute

\section{Source}

National Cancer Institute. Cerebellar and Fourth Ventricle Ependymal Tumor. NCI

Thesaurus. Code C131597.

An ependymal tumor affecting the cerebellum and fourth ventricle and the brain. 